\title{
How can abortion be made simpler for women?
}

\author{
Vincent Argent
}

\begin{abstract}
Background
It is general policy to make abortion simpler for women by promoting direct access, improved services and National Health Service (NHS) funding. Putting abortion at the forefront of sexual health practice would assist this objective.
\end{abstract}

\section{Recommended service arrangements}

Clearly women should expect that providers comply with the recommended service arrangements laid down in the Royal College of Obstetricians and Gynaecologists EvidenceBased Clinical Guidelines on The Care of Women Requesting Induced Abortion. ${ }^{1}$ Minimum standards include assessment within 5 days of referral and the abortion procedure no more than 3 weeks from the referral. The Guidelines suggest telephone referral systems and a formal care pathway with arrangements for access from a wide range of referral sources, not just general practitioners (GPs). The Department of Health and the Medical Foundation for Aids and Sexual Health (MedFASH) have recently published standards for abortion services provision. ${ }^{2}$

\section{British Medical Association view}

The British Medical Association briefing paper on abortion time limits in 2005 made many useful suggestions such as law reform including abortion on request up to 14 weeks' gestation, the extension of the current law to Northern Ireland, as well as provisions to improve access to early and late abortions. ${ }^{3}$ In 2005, the House of Commons Science and Technology Committee discussed human reproductive technologies and the law, and examined the scientific, medical and social changes in relation to abortion that have taken place since $1967 .{ }^{4}$

\section{Direct access}

Direct access to abortion services has been recommended to allow earlier access to client-friendly providers. Direct access should be encouraged with the help of advertising and action lines. Suitable advertisements could be placed in prominent public places, on public transport, in pubs and clubs, and in GP health centres. More use should be made of women's magazines.

Many women prefer to go directly to an abortion provider for speed of access but also because they do not wish to inform their GP of their action.

The General Medical Council (GMC) usually recommends that patients should be referred by their GPs to specialist services. Section 45 of the Good Medical Practice publication states that: "If the patient has not been referred to you by a general practitioner, you should inform the general practitioner before starting treatment, except in emergencies or when it is impracticable to do so". 5

These arrangements are clearly overridden by confidentiality and health care needs, especially in fields such

J Fam Plann Reprod Health Care 2006; 32(2): 67-69

East Sussex Hospitals NHS Trust, Eastbourne District General Hospital, Eastbourne, UK

Vincent Argent, FRCOG, LLB, Consultant Gynaecologist and Medical Director, bpas

Correspondence to: Dr Vincent Argent, Department of Obstetrics and Gynaecology, Eastbourne District General Hospital, Kings

Drive, Eastbourne, East Sussex BN21 2UD, UK.

E-mail: vincent_argent@hotmail.com as contraception, sexual health and induced abortion where direct access is endorsed by the GMC.

There are still an appreciable number of GPs who have conscientious objection to abortion or are just not keen on involvement in this aspect of women's health care. Section 6 of Good Medical Practice clearly states that: "If you feel that your beliefs might affect the advice or treatment you provide, you must explain this to patients, and tell them of their right to see another doctor". 5 Direct access would be of considerable benefit to women whose GPs hold these views.

Many young women, especially students and visitors, are not registered with a GP. Women generally know what they want and prefer good access to a supportive service.

Fast-track services and rapid referral systems should be encouraged and promoted using the 'Choose and Book' system.

The MedFASH Recommended Standards for Sexual Health Services describe the implications for service planning. ${ }^{2}$ Primary care trusts should monitor access to abortion services and ensure that of the total number of abortions and the percentage performed under 10 weeks' gestation meet national performance target thresholds. In 2004 , performance was banded as 'good' if $70 \%$ or more abortions took place at less than 10 weeks, with 'average' being $45-60 \% .^{2}$

\section{Earlier abortion}

Direct referral will lead to abortions being done at earlier gestations. Many women would like to have the procedure as soon as possible. The earlier the gestation, the safer the abortion, but there is some risk of ongoing pregnancy and missed ectopic pregnancies. Good follow-up advice is essential.

\section{Taking the stigma out of abortion}

One in three women will have an induced abortion. It is the most common procedure in gynaecological practice. Abortion should be seen as a fact of life, especially for the majority of women in modern Britain. Abortion services should be mainstream and upfront, and not be treated as an unwelcome part of practice.

Specialists in sexual and reproductive health and gynaecology should be proud to lead induced abortion services. Many colleagues find other fields, such as assisted conception, oncology and fetal medicine, more attractive and few specialist registrars see themselves as future leaders of abortion services. When will the UK see its first Professor of Induced Abortion?

\section{Specialist services}

Dedicated specialist services already exist in the private charitable sector. These centres are run by staff committed to abortion practice. Sometimes NHS staff are not so keen to get involved but there is no doubt that dedicated induced abortion services should be available to all women. Such NHS services are often run in conjunction with the charitable providers. Such dedicated units generally have better outcomes and lower complication rates.

\section{National and international travel}

Abortion law is far more restrictive in Northern Ireland and Eire. Women are fully entitled to travel to other European Economic Area member states for health care. If such 
countries feel unable to relax their laws, then such travel should be facilitated; such arrangements already exist.

Even in England and Scotland, women often have to travel long distances to access the services they need; funded travel would assist in these cases.

\section{Training future practitioners}

A great step forward has been taken in the training of future practitioners in this important area of medical practice. The Faculty of Family Planning and Reproductive Health Care (FFPRHC) is designing a syllabus for Certificates in Abortion Care, which will introduce eight competencybased practical sections to cover outpatient consultation and the various abortion methods (FFPRHC personal communication, 2006). The Faculty recognises that doctors and nurses who take part in abortion care come from a variety of backgrounds such that a standardised training programme is essential. The syllabus aims to ensure that women have good access to services staffed by nurses and doctors competent in abortion care, supported by other staff within a wider team, who understand and can provide nondirective and accurate information to deliver a comprehensive and holistic service.

\section{Nurse practitioners to sign HSA 1 forms}

It is sometimes difficult to find doctors who are willing to sign the HSA 1 forms.

The Abortion Regulations 1991 in Regulation 3 deals with the certification of the necessary medical opinions under the Act. ${ }^{6}$ Except in an emergency, two doctors must be of the opinion that the termination of pregnancy is warranted under the terms of the Act and they must sign the HSA 1 form. The doctors are not required themselves to see or examine the woman concerned.

Since 1967, and especially in recent years, nurse practitioners have increasingly taken on roles formerly only carried out by registered medical practitioners. It would be quite sensible to allow trained nurse practitioners not only to undertake the counselling and pre-operative assessment of women but also to allow them to sign the HSA 1 form.

This amendment could be added to the forthcoming proposals to amend the Human Fertilisation and Embryology Act $1990 .^{7}$ Abortion lobbyists would strive for the right of women to access abortion on request, especially in the first 12 weeks, thus bringing us in line with North America and several European countries. The requirement for the two signatures would be abolished.

\section{Nurse practitioners to perform surgical abortions}

Nurse practitioners are increasingly performing preassessment consultations and there is positive feedback on their role.

Current law may in fact allow nurse practitioners to actually perform surgical abortions. The involvement of nurses in abortions was raised in the Royal College of Nursing vs. Department of Health and Social Security (1981) case. ${ }^{8}$ It is often thought that this judgement only allows nurses to provide medical abortion but this is not the correct interpretation of this authoritative case in the House of Lords. It is only necessary for a doctor to be in overall charge of the process. It was said that a nurse is "fully protected provided that the entirety of the treatment for the termination of pregnancy and her participation in it is at all times under the control of a doctor even thought the doctor is not present throughout the entirety of the treatment".

In America, nurses have been trained to perform manual vacuum aspiration and the next step would be to train nurse practitioners to perform first-trimester surgical suction abortions.

\section{Late abortions}

Access to late abortions up to 24 weeks is very difficult because so few providers can offer this service. The recent Chief Medical Officer's report on late abortion has requested that the Department of Health should produce best practice guidelines on late abortion which include advice and pathways for late abortion. ${ }^{9}$

There are some different definitions of 'late' abortion. Abortions become far less common with advancing gestational age. In 2003, the total number of abortions in England and Wales was 181600 , with 158449 performed before 12 weeks and 9328 at 13-19 weeks. There were only 2927 abortions carried out at 20-24 weeks, the majority for fetal abnormality. In 2002, there were only 84 abortions carried out after 24 weeks, the majority for quite severe fetal abnormality and only a few because of grave risk to the health or life of the mother.

\section{NHS funding}

NHS funding for all abortions should be the norm. The previous lack of funding or unfair means testing should be addressed. Commissioners should regard funded abortion as an essential part of the sexual health strategy. Currently about $80 \%$ of abortions performed in the charitable sector are NHS funded.

\section{Abortions in the community and over-the-counter abortifacients}

Medical abortion may be provided by suitably registered health centres. The need for such registration could be removed. Will medical abortifacients ever be available over the counter in a similar fashion to postcoital contraception? This would require repeal of the Offences Against the Persons Act 1861 to decriminalise abortions performed by the woman herself. ${ }^{10}$ One might indeed ask why abortion is still subject to a law passed in 1861 at a time when any discussion of such matters was highly taboo.

\section{Women themselves}

In general, women will increasingly demand simpler access to abortion services and this will promote good sexual health.

Statements on funding and competing interests

Funding. None identified.

Competing interests. Dr Argent is the Medical Director of bpas.

References

1 Royal College of Obstetricians and Gynaecologists (RCOG). The Care of Women Requesting Induced Abortion (National Evidence-Based Clinical Guideline No, 7). London, UK: RCOG Press, 2004. http://www.rcog.org.uk/resources/Public/pdf/induced_abortionfull.pdf [Accessed 15 February 2006]

2 Medical Foundation for Aids and Sexual Health (MedFASH). Recommended Standards for Sexual Health Services. Standard 9: Abortion services provision. London, UK: Department of Health, 2003.

3 British Medical Association (BMA). Abortion Time Limits. A Briefing Paper from the BMA. London, UK: British Medical Association, 2005.

4 House of Commons Science and Technology Committee. Human Reproductive Technologies and the Law. Fifth Report of Session 200405, Vol. 1, HC 7-1. London, UK: The Stationery Office, 2005; Recommendation 77 .

5 General Medical Council (GMC). Good Medical Practice (3rd edn). London, UK: GMC, 2001.

6 The Abortion Regulations 1991 (Statutory Instrument 1991 No. 499). London, UK: The Stationery Office, 1991.

7 Response by the Human Fertilisation and Embryology Authority (HFEA) to the Department of Health's Consultation on the Review of the Human Fertilisation and Embryology (HFE) Act. London, UK: HFEA, 2005. http://www.hfea.gov.uk [Accessed 15 February 2006].

8 Royal College of Nursing of the United Kingdom vs. Department of Health and Social Security 1981 CA. In: Kennedy I, Grubb A (eds), Medical Law (3rd edn). London, UK: Butterworths, 2000.

9 Department of Health. An Investigation into the British Pregnancy Advisory Service (BPAS) Response to Requests for Late Abortions: A Report by the Chief Medical Officer. London, UK: Department of Health, 2005.

10 Offences Against the Persons Act 1861 (24 \& 25 Vict., c.100). 